\title{
Proposição de um diálogo acadêmico no formato revista: Educação e Pesquisa
}

Vários desafios têm colocado os pesquisadores da área de Educação diante da necessidade de dedicar atenção a novos temas, a cruzamentos de diferentes abordagens ou à transposição de análises de um nível de ensino para outro. Entre esses novos desafios, figura a ampliação do acesso ao Ensino Superior, que tem instigado a busca de compreensão de problemas específicos desse nível de ensino, cada vez mais erigidos a objetos de estudos sob diferentes perspectivas. Com isso, a pesquisa em Educação tem ganhado em produtividade, da qual os artigos publicados neste número de Educação e Pesquisa são representativos.

Como exemplo da novidade motivada pelos novos desafios a que os pesquisadores estão respondendo, o artigo Os métodos quantitativos no Ensino Superior: uma tipologia de representações, de Madalena Ramos e Helena Carvalho, volta-se para a investigação sobre o ensino de matemática no terceiro grau a partir de uma perspectiva que até recentemente era usada apenas para análise do Ensino Fundamental e Médio.

Perante a necessidade de intervir pedagogicamente no processo de ensino e aprendizagem de alunos que apresentem maiores dificuldades em construir uma boa relação com disciplinas ligadas aos métodos quantitativos, as autoras lançam-se à pesquisa a partir de duas perguntas complementares: Quais são as representações que os estudantes universitários constroem das disciplinas da área científica dos Métodos Quantitativos? Como alunos de cursos diferentes estabelecem suas representações dessas disciplinas?

As respostas obtidas pelas autoras, ou por outras pesquisas que venham a ser desenvolvidas inspiradas no trabalho aqui publicado, poderão contribuir para o desenvolvimento de estratégias de intervenções que proporcionem aos alunos a ampliação de suas possibilidades de sucesso nas disciplinas quantitativas.

Ainda motivadas pelos desafios trazidos pela ampliação do acesso à escolarização de mais longa duração, em Análise do processo de exame de grau na pós-graduação stricto sensu, as autoras Silvana Pezzi e Andrea Valéria Steil apresentam uma resposta à demanda de pesquisa sobre um aspecto da pós-graduação. Pode-se dizer que o aumento do número de cursos de pós-graduação stricto sensu, por si só, já aguça a curiosidade investigativa de quem atua em Educação. No caso do presente trabalho, toca-se em temática bastante presente no cotidiano dos docentes dos programas de pós-graduação brasileiros: a análise da qualidade de dissertações e teses.

As autoras apresentam, por meio de bibliografia sobre o assunto e de suas análises, uma reflexão que vem se somar ao conhecimento acumulado no fazer cotidiano dos docentes que atuam nos cursos de pós-graduação no Brasil. Tal conhecimento é atualizado e reelaborado, por exemplo, a cada processo seletivo para ingresso na pós-graduação, quando se questiona qual projeto corresponde melhor ao que pode se entender por 
uma pesquisa de mestrado ou doutorado. 0 mesmo processo ocorre a cada composição de banca examinadora de dissertação ou tese, quando se pondera sobre qual examinador aportará as melhores contribuições para o avanço da pesquisa em curso, no caso dos exames de qualificação ou para o aprofundamento ou a continuidade da pesquisa concluída quando se trata de defesa.

Embora seja certo afirmar, como fazem as autoras, que há poucos estudos no Brasil que tomam para análise o exame de grau, é correto considerar também que o acúmulo de discussões no fazer cotidiano da universidade contribui para a produção de conhecimento sobre o assunto. lsso pode ser notado no fato de que, em algumas instituições, o exame de grau encontra-se em um estado mais elaborado que em outras como apontam as autoras.

Trata-se, portanto, de estudo que contribui para o surgimento de novas pesquisas que possibilitem verificar em que direções se pode caminhar com a pós-graduação a partir de uma necessidade de mudança apontada nos trabalhos que estudam os eventos de avaliação de grau e, consequentemente, da consideração do que seja a produção esperada em um curso de mestrado ou doutorado.

No trabalho de Ramon de Oliveira, Possibilidade do Ensino Médio integrado diante do financiamento público da Educação, publicado na sequência, pode-se verificar vínculos com os dois anteriores e reforçar a relação entre eles pela preocupação relacionada à qualidade do ensino e pela busca de estabelecimento de condições para a construção dessa qualidade.

A relação entre os três textos pode ser apresentada em poucas palavras: o autor assegura que uma "concepção de formação profissional e de nível médio" precisa estar articulada ao "financiamento público desse nível de ensino", de modo a que se garanta o "acesso aos saberes indispensáveis à formação técnica” bem como à "apropriação de conhecimentos e à vivência de práticas que contribuam para a atuação na sociedade”.

Isso também pode ser dito, com pequenas adaptações, tanto com respeito a uma melhor interação dos alunos do Ensino Superior com as disciplinas ligadas aos métodos quantitativos quanto com relação ao estabelecimento de critérios mais fortemente definidores de qualidade quando se trata de exame de grau nos cursos de pós-graduação.

Para além da preocupação básica que pode valer para qualquer nível de ensino, o autor contribui principalmente para uma reflexão crítica sobre a dualidade da formação no Ensino Médio - geral ou técnica -, assim como para com o tratamento dispensado a esse nível de ensino por parte das políticas públicas. A continuidade na leitura dos três textos se dá também pela relação intrínseca entre a qualidade do Ensino Médio e a qualidade do Ensino Superior.

Entendendo a revista como um objeto portador de textos que pode ser tomado pelo leitor como um espaço de estabelecimento de diálogo entre autores e perspectivas, os três textos seguintes, lidos em conjunto, podem fomentar a reflexão pelas suas aproximações e pelos seus distanciamentos. Além do diálogo possível no subconjunto, também podem ser articulados com os demais em torno do eixo da qualidade nos diferentes níveis de ensino.

Em Estratégias educativas de internacionalização: uma revisão da literatura sociológica, a autora Andréa Aguiar estuda a procura pela escolarização internacional por famílias mais favorecidas 
socialmente com vistas a transformar o capital econômico em capital cultural. Segundo a autora, a "produção do campo da Sociologia da Educação tem confirmado [...], quanto maior a posse de recursos materiais e simbólicos, maiores são as chances de 'acerto' nos investimentos que concernem à educação escolar, na medida em que tais recursos habilitam os sujeitos a melhor discriminar suas diversas possibilidades, a fazer escolhas pertinentes, a investir em alvos específicos e deles tirar o maior proveito possível”.

Ferramenta de autoria multimídia para ensino de língua estrangeira em ambiente multiagente, de Adroaldo Guimarães Rosseti et al., consiste na apresentação de um processo de construção de ferramentas multimídia para o ensino de língua estrangeira. Os autores justificam a necessidade de criação dessas ferramentas na dificuldade das escolas públicas e privadas em lograr sucesso no ensino de idiomas.

Na medida em que os dois textos tocam na questão de aquisição de bens simbólicos, dentre eles o conhecimento de uma língua estrangeira, lidos em conjunto e considerados os estudos evocados em ambos os textos, os dois trabalhos contribuem para a reflexão sobre as diferentes concepções de sucesso em função das diferentes estratégias usadas ou propostas para obtê-lo.

Em Trajetória de herdeiro entre dois projetos políticos, Agueda Bernardete Bittencourt penetra na história da Educação a partir da análise da trajetória intelectual e social do educador Anísio Teixeira com base em fontes primárias que acabam por revelar o importante papel da circulação internacional dos intelectuais na sua formação. Trata-se, portanto, de estudo sobre uma trajetória intelectual de sucesso inegável, que pode complementar a discussão suscitada pelos dois textos anteriores. Na medida em que nos apresenta os percursos de origem social e cultural e os caminhos traçados por Anísio Teixeira, a autora evidencia as tensões derivadas das expectativas do projeto familiar desenhado para esse educador e dos confrontos regionais e de origem social por ele vivido. Revela, desse modo, os desdobramentos políticos do percurso de Anísio Teixeira ao se relacionar com intelectuais de outros estados e países, os quais acabam também por expressar e configurar a educação brasileira. Ao articular as origens familiar, cultural e política do educador e sua inserção internacional, a autora revela, em sua trajetória, a sua influência direta nas políticas de formação da pós-graduação em nosso país. Levando em cosinderação os investimentos na pós-graduação dos órgãos de fomento na formação de pesquisadores feita no exterior, o tema ganha especial relevância.

No contexto da reflexão sobre os diferentes níveis de ensino, a universidade volta ao foco na perspectiva de análise de sua produção. A pesquisa nas ciências sociais e seus métodos é tema recorrente em periódicos da Educação e devem ser estimulados na busca de ampliar o rigor das investigações nesse campo. Foi abordado em dois dos artigos selecionados para este número da Revista. 0 primeiro, A sala de aula como campo de pesquisa: aproximações e a utilização de equipamentos digitais, de Oldimar Cardoso e Sonia Teresinha de Sousa Penin, aborda o uso de tecnologias avançadas no trabalho de campo na pesquisa educacional. No segundo, Método do caso e de case: a trajetória de uma ferramenta pedagógica, Maria Arlinda de Assis Menezes discorre sobre as diferenças e os contextos de uso das duas perspectivas de pesquisa e entre os modos de pensamento empírico e dedutivo como fatores de diferenciação entre o ensino angloamericano e europeu. 
0 texto de Oldimar Cardoso e Sonia Teresinha de Sousa Penin discute o potencial de uso dos recursos tecnológicos na coleta de dados da pesquisa educacional, reforçando os ganhos quanto ao rigor, à coerência metodológica e à objetividade. Com base no diálogo com a literatura sobre pesquisa de campo, o autor analisa os desafios da observação em sala de aula, atendo-se a conceitos do campo antropológico. Tendo por foco investigações desenvolvidas em salas de aula paulistas e francesas, apresenta os equipamentos digitais utilizados - como palmtops, gravações em áudio e câmera, fotografias digitais, smartphones, entre outros -, mostrando o potencial facilitador destes, mas também quando orientado por uma metodologia, as possibilidades de ampliação do rigor e da validade, ao multiplicar os tipos de fontes de dados. Apresenta procedimentos como elaboração de notas de campo digitais e uso de vídeogravações digitais, revelando as vantagens que oferecem diante das questões de rigor e das facilidades técnicas que oferecem. Reforça ainda que a conquista da "solidariedade" e "camaradagem" dos atores de campo pode ser facilitada pelo uso de tais equipamentos, pois estes permitem registros informais, a observação das gravações de seus discursos pelos atores, auxiliando no confronto com suas práticas cotidianas. Por fim, discute, com base nos exemplos dados ao longo do texto, a diferença entre observação e intervenção, e como o uso dessas tecnologias pode auxiliar na reflexão sobre a objetividade da pesquisa, não deixando que a observação fique refém da autoridade do pesquisador.

A diferenciação entre método do caso e estudo de caso é importante no contexto de formação de pesquisadores no âmbito das Ciências Sociais. Ao se dedicar a essa tarefa, Maria A. A. Menezes aponta o comportamento do primeiro com uma estratégia de ensino, enquanto que o segundo se constitui como uma estratégia de pesquisa. Com relação ao "estudo de caso", a autora toma como referência o trabalho de R. K. Yin e apresenta alguns aspectos dessa metodologia de investigação científica. Debruçando-se de forma mais acentuada sobre o método do caso a partir do trabalho de C. C. Langdell, indica ser este muito usado nas ciências sociais aplicadas, a exemplo do Direito e da Administração, como ferramenta didático-pedagógica, indicando também seu potencial. Enfatiza em sua análise o uso dos chamados cases no contexto brasileiro, nas áreas já citadas e também na Saúde, como metodologia que parte da experiência e de realidades vivenciadas e confronta teoria e prática. Ressaltando a tradição dedutiva no modo de pensar e ensinar no Brasil, afirma que ainda assim o "método do caso" pode se constituir como uma "nova mentalidade" no processo pedagógico de formação acadêmica em nosso país.

É ainda dentro da perspectiva de análise da produção acadêmica brasileira que o artigo Educação ambiental crítica: do socioambientalismo às sociedades sustentáveis, de Gustavo Ferreira da Costa Lima, insere-se. 0 tema é central no âmbito do fervente debate do campo da educação ambiental - EA - e o artigo fornece sólido panorama sobre seu estado da arte. Trata-se de revisão teórica da literatura em torno dos desdobramentos da educação ambiental e da educação para o desenvolvimento sustentável, proposta pela UNESCO. Apresenta o contexto histórico que serve de panorama de fundo para a construção do que hoje se chama educação ambiental crítica no Brasil. A partir da problematização do que se convencionou chamar de educação ambiental conservadora em nosso país e de sua caracterização, o autor apresenta o diálogo, as divergências e os argumentos formulados por aqueles que defendem a educação ambiental crítica em oposição à anterior. Analisa, desse modo, o conjunto de aspectos epistemológicos, pedagógicos, políti- 
cos e éticos envolvidos em tais argumentos, indicando os principais propostos pela EA crítica em contraposição à conservacionista. Tais argumentos, como nos mostra o autor, levaram a adjetivação da EA em crítica, transformadora, popular, emancipatória que, ao fim e ao cabo, denotam a insatisfação com o reducionismo da perspectiva conservadora. 0 autor discorre também sobre a relação entre EA, desenvolvimento sustentável e sociedade sustentável, afirmando que a educação para o desenvolvimento sustentável proposta pela UNESCO e outros setores sociais tinham interesse na manutenção do status quo e numa sustentabilidade orientada pelas forças do mercado. Afirma assim que o pensamento crítico tende a rejeitar a educação para o desenvolvimento sustentável e defende outra concepção político-pedagógica de maior complexidade baseada nos valores da diversidade cultural, da autonomia política e da democracia participativa. Em suma, sublinha, com base na perspectiva histórica, as matrizes filosóficas, as posições político-pedagógicas e as forças sociais que inspiraram a emergência da EA crítica e o impacto desse movimento sobre a relação entre educação, sociedade e meio ambiente no contexto brasileiro.

Os autores Carmen Lúcia Souza Barros e Tarso Bonilha Mazzotti, no artigo Profissão docente, uma instituição psicossocial, analisam respostas dadas a um questionário para verificar a existência de lideres profissionais entre os professores. Com foco em uma pergunta central - "Com quem você conversa quando tem dúvidas a respeito de educação/ensino?” -, reúnem condições de compreender se há ou não lideranças entre os professores. Os resultados estimulam um relevante debate em torno da configuração de uma profissão docente ou não. Embora a contribuição principal do artigo esteja relacionada à implementação de propostas de avaliação e regulação nas escolas, a posição bem delimitada dos autores certamente poderá suscitar novas pesquisas, em especial sobre formação de professores e autonomia intelectual. Desse modo, o artigo pode dialogar com as recentes preocupações sobre a expansão do ensino universitário presentes em outros textos deste número.

A produção acadêmica tem como uma de suas principais funções fornecer elementos para reflexão sobre práticas educativas concretas, especialmente aquelas voltadas para a formação. Fruto da tese de doutorado de Luciana Esmeralda Ostetto, o texto Na dança e na educação: o círculo como princípio analisa criticamente uma experiência de desenvolvimento de processos educativos e formativos de educadores e suas relações com um gênero específico de dança: a circular. Trata-se de temática pouco presente nos espaços de educação em geral e na arte e educação. No trabalho, a autora discorre sobre a dimensão pedagógica do ensino de dança por meio da potencialidade do símbolo circular, teorizado a partir de referências iconográficas e mitológicas, dos estudos jungianos acerca da mandala e das tradições espirituais de diferentes povos. Em síntese, as propriedades simbólicas do círculo como perfeição, ausência de divisão, equilíbrio, totalidade, integração e interdependência são evocados para problematizar perspectivas e valores que orientam as práticas pedagógicas dos professores. Para tal, recolhe dados com base em encontros com educadoras e utiliza-se de elementos de seu quadro conceitual - o círculo - para construção da metodologia da pesquisa. Destaca a oportunidade formativa da experiência com a dança circular que promove vivências coletivas para manifestação de novas sensibilidades, a partir da expressão corporal e artística, as quais por sua vez são promotoras de relações entre estética e prática escolar. Seus dados revelam o apren- 
dizado da circularidade como processo pelas educadoras, e também reconhece o desafio da mudança de atitude. No entanto, aposta na importância de se discutir a circularidade nos processos educativos.

As travessias da aula de campo na geografia escolar: a necessidade convertida para além da fábula, de Christian Dennys Monteiro de Oliveira e Raimundo Jucier de Souza, é um artigo que aborda o trabalho de campo no ensino de geografia a partir de uma retrospectiva histórica, apresentando diferentes concepções sobre essa prática com base em autores que se debruçaram sobre o tema. Considerando que as escolas realizam de maneira acentuada as aulas em campo, torna-se fundamental uma reflexão sobre estas pelos professores. Além disso, tais práticas ocupam papel importante nos currículos de geografia e na formação dos conceitos geográficos. Não por outra razão, há hoje a preocupação de vários autores em construir uma teoria das aulas em campo. Sua força pedagógica, segundo os autores do artigo, encontra-se na capacidade de interação professor-aluno em aprender com o mundo e planejar-se no improviso, na novidade que a experiência do contato com a natureza proporciona.

Valdir Heitor Barzotto

Martha Marandino 